\title{
Effect of Photodynamic Therapy Enhanced by Methylene Blue on Drug-resistant Mycobacterium smegmatis
}

\author{
Bohyun Jeong ${ }^{1}$, Jiyeun Kate Kim¹, Taeok Bae², Indal Park ${ }^{1 *}$ \\ 'Department of Microbiology, Kosin University College of Medicine, Busan 49267, Republic of Korea \\ ${ }^{2}$ Department of Microbiology and Immunology, Indiana University School of Medicine-Northwest, Gary, IN 46408 USA
}

\author{
Corresponding \\ Indal Park, Professor \\ Department of Microbiology, Kosin \\ University College of Medicine, 262 \\ Gamcheon-ro, Suh-gu, Busan 49267, \\ Republic of Korea \\ Phone : +82-51-990-6423 \\ Fax : +82-51-990-3081 \\ E-mail : indalp103@gmail.com
}

Received : November 5, 2020

Revised : November 25, 2020

Accepted : November 26, 2020

No potential conflict of interest relevant to this article was reported.

Copyright (C) 2020 Journal of Bacteriology and Virology

(C) This is an Open Access article distributed under the terms of the Creative Commons Attribution Non-Commercial License

(http://creativecommons.org/

license/by-nc/3.0/).
Tuberculosis (TB) is an old disease caused by Mycobacterium tuberculosis. Although it has been known for humans for thousands of years, the treatment of this disease still requires a lengthy therapy with multiple antibiotics. Also, the emergence of multidrug-resistant strains made it more difficult to treat TB, calling for a novel treatment approach. In Photodynamic therapy (PDT), a photosensitizer, such as methylene blue (MB), is irradiated by a laser, generating reactive oxygen species and killing microorganisms. Here, using $M$. smegmatis as a model mycobacterium, we examined the utility of PDT in TB treatment. The photosensitizer $\mathrm{MB}$ alone showed weak antimicrobial activity; however, when irradiated by a laser, it efficiently killed $M$. smegmatis (> 97\% killing with $30 \mathrm{mg} / \mathrm{ml} \mathrm{MB}$ and 54 $\mathrm{J} / \mathrm{cm}^{2}$ irradiation). Surprisingly, PDT showed more efficient killing activity toward drug-resistant strains of $M$. smegmatis than the drug-sensitive wild-type strain. In PDT, when the irradiation step alone (Intermittent PDT) or the entire PDT process was repeated (Repeated PDT), the bactericidal activity was significantly enhanced. Since PDT can be applied locally in a short period of time and kills mycobacterium irrespective of its antibiotic resistance status, we conclude that PDT can be a viable option for TB treatment.

Key Words: Tuberculosis, Mycobacterium smegmatis, Drug resistance, Photodynamic therapy, Methylene blue

\section{INTRODUCTION}

Tuberculosis (TB) is caused by Mycobacterium tuberculosis ( $M$. tuberculosis), which mainly infects the lungs but can also infect other organs. Although TB can be cured in most cases, it requires antibiotics treatment for six months, or a longer period (1). Moreover, the emergence of drug-resistant $M$. tuberculosis makes it hard to cure TB with first-line drugs (2). When infection was caused by $M$. tuberculosis resistant to isoniazid and rifampicin, it is defined as multi-drug resistant tuberculosis (MDR-TB), which requires at least 9 - 20 months of treatment. The long treatment period and the severe drug side effects lower the probability of cure (1). For MDR-TB treatment, the use of second-line drugs such as fluoroquinolone (FQ) is enforced. However, when the infection was caused by MDR-TB bacterium resistant to $F Q$ and at least one of the injectable drugs such as capreomycin, kanamycin, and amikacin, it is defined as extensively drug-resistant tuberculosis (XDR-TB) $(1,2)$. 
According to the World Health Organization (WHO), in 2018, about 10 million people suffered from TB, and 1.45 million people died from TB. Moreover, 500,000 new rifampicin-resistant TB cases were reported in 2018, and 78\% were MDR-TB. (1) In South Korea, 23,821 new cases were reported in 2019. Among those cases, 580 were MDR-TB, and 33 were XDR-TB. (3) This indicates that, for effective TB treatment, along with the conventional anti-TB drugs, new therapeutics are required.

One such promising therapeutic for TB is Photodynamic therapy (PDT). PDT needs the following three components: light, photosensitizer, and molecular oxygen. (4) In PDT, luminescent light excites the specific photosensitizer and forms singlet oxygen; then, the singlet oxygen induces apoptosis or necrosis of cells (5-7). PDT has been officially recognized as a cancer treatment by the Food and Drug Administration (FDA) in the US in 1995, and has been used in various cancer treatments worldwide (8-10). Although currently, PDT is primarily used to treat cancer, antimicrobial PDT (APDT) is also receiving considerable attention in treating microbial infections (11-14). The major attraction of APDT over conventional antibiotics is that multidrug-resistant strains are as easily killed as sensitive strains. Moreover, due to the production of multiple forms of ROS during PDT, it is less likely that APDT suffers from the resistance problem (14).

PDT has been used to kill mycobacteria or to treat mycobacterial infections. Wiegell, S. G. et al. reported the treatment of granuloma caused by M. marinum with PDT (15) O'Riordan K. et al. also showed that PDW with benzoporphyrin derivative as a photosensitizer could kill $M$. bovis BCG in vitro and a murine granuloma model (16). More recently, using clinical isolates of $M$. tuberculosis strains, Sung N. et al. demonstrated that PDT with radachlorin as a photosensitizer could kill not only wild type but also MDR and XDR strains (17).

The TB incidence is high in resource-scarce countries. For the PDT-mediated TB treatment in such countries, therefore, an inexpensive photosensitizer is preferred. One of such photosensitizers is methylene blue (MB). As a phenothiazinium salt, MB was officially approved as PDT photosensitizer for the treatment of oral infectious diseases (18-20). Compared with other photosensitizers used in previous mycobacterial studies, MB is inexpensive and poses a low barrier to clinical application in resource-scarce settings. It also efficiently absorbs red light (e.g., $660 \mathrm{~nm}$ ), which can penetrate tissue more efficiently than shorter wavelength lights.

In the previous study, we showed that methylene blue (MB) is an effective photosensitizer for PDT in killing M. smegmatis, a model organism with high genetic similarity to $M$. tuberculosis (21). Also, we found that ciprofloxacin-resistant $M$. smegmatis was more sensitive to PDT, as compared with WT M. smegmatis. However, it remained to be determined whether the higher susceptibility of ciprofloxacin mutant can be generalized to MDR strains of M. smegmatis.

To answer the question, in this study, we take advanced of the fast growth of $M$. smegmatis and generated various isogenic MDR strains from the same parent $M$. smegmatis strain and examined the effect of the mutations on the sensitivity to PDT. Also, we examined whether the addition radiation step or repeat of the whole PDT process could increase the bactericidal potency of PDT. We found that, in general, MDR strains showed higher sensitivity to PDT. We also found that repeat of radiation significantly increases the bactericidal potency of PDT.

\section{MATERIALS AND METHODS}

\section{Bacterial strains and antibiotics}

In this study, M. smegmatis NCTC8159 was used. M. smegmatis has 2000 homologous genes with M. tuberculosis, the causative agent of TB. $M$. smegmatis is considered a typical surrogate model for $M$. tuberculosis because of its rapidly-growing and non-pathogenic character. $(22,23)$ The bacterium was grown in Middlebrook 7 H9 (Difco, USA) broth and 7H10 (Sigma, USA) plate containing OADC (oleic acid, albumin, dextrose, catalase; Sigma-Aldrich) and 0.05\% Tween 
80 (Sigma, USA). When necessary, the following antibiotics were used: Ciprofloxacin (Ildong pharmaceutical Co Ltd, Korea), levofloxacin (Jeil pharmaceutical Co Ltd, Korea), moxifloxacin (Bayer Korea, Korea), rifampicin, ethambutol, streptomycin (Sigma-Aldrich Co., USA), isoniazid (Fluka, USA), kanamycin (Yuhan Co Ltd, Korea).

\section{Generation of multi-drug resistant $M$. smegmatis}

We first generated multi-drug resistant $M$. smegmatis (MDR-M. smegmatis) resistant to isoniazid and rifampicin. Fluoroquinolone (FQ) resistant MDR-M. smegmatis was generated through the stepwise-selection method. (24) The initiated minimal inhibitory concentrations of ciprofloxacin and moxifloxacin were $0.125 \mu \mathrm{g} / \mathrm{ml}$. Then $M$. smegmatis was grown in the presence of $0.25 \mu \mathrm{g} / \mathrm{ml}$ of ciprofloxacin or moxifloxacin. When resistant mutants arose, they were grown in the presence of a two-fold higher concentration of the antibiotics. The highly resistant mutants were isolated through repeated trials and amplification. The mutants were washed with PBS, aliquoted in 1 $\mathrm{ml}$ of $20 \%(\mathrm{vol} / \mathrm{vol})$ glycerol (Sigma, USA), and stored at $-80^{\circ} \mathrm{C}$. Three aliquots were randomly picked and spread on $7 \mathrm{H} 10$ plates to count the CFU.

\section{Drug susceptibility test}

The selected resistant mutants were subjected to susceptibility tests in 96-well plates. Ciprofloxacin, moxifloxacin, levofloxacin, isoniazid, ethambutol, rifampicin, streptomycin, and kanamycin were used from $128 \mu \mathrm{g} / \mathrm{ml}$ to $0.125 \mu \mathrm{g} / \mathrm{ml}$ of concentration by two-fold dilution. The $96-$ well plates containing the mutants and anti-biotics were incubated at $37^{\circ} \mathrm{C}$ for two days. The concentrations of antibiotics that the mutants were no longer amplified were noted as MICs.

\section{PCR (Polymerase chain reaction) test and DNA sequencing}

The wild-type strain and drug-resistant mutants were grown in $5 \mathrm{ml} 7 \mathrm{H} 9$ broth. The resulting cultures were centrifuged and washed with PBS twice. The pellet was suspended in $50 \mathrm{ml}$ of distilled water and incubated at $95^{\circ} \mathrm{C}$ for $5 \mathrm{~min}$. This suspension was centrifuged at 14,000 rpm for $10 \mathrm{~min}$, and the supernatants were used for PCR reaction. The genes gyrA and $g y r B$, which are associated with fluoroquinolone resistance, were detected with primer gyrAF, gyrAR, gyrBF, and gyrBR (Table 1). The katG gene, which is associated with isoniazid resistance, was detected with primer katGF, katGR. The rpoB gene, which is associated with rifampicin resistance, was detected with primers rpoBF, and rpoBR. PCR was carried out with Takara thermal cycler and G-Taq premix (COSMOgenetech, Korea). The amplification condition was as follows: $95^{\circ} \mathrm{C}$ for $20 \mathrm{sec}$ (denaturation), 55 $\mathrm{C}$ for 20 (annealing), $72^{\circ} \mathrm{C}$ for $1 \mathrm{~min}$ (elongation), and $30 \mathrm{cycles}$. The PCR-amplified products were sequenced by COSMOgenetech using ABI PRISM 3730XL Analyzer (Applied Biosystems, USA).

Table 1. Primers used in this study

\begin{tabular}{cl}
\hline Primer name & \multicolumn{1}{c}{ Sequence } \\
\hline gyrAF & 5'-CGC TTC CTG GAT GTT TAA CCC G-3' \\
gyrAR & 5'-CAG CTC CTT AGC TCG GGC C-3' \\
gyrBF & 5'-GGC ATG TAC ATT GGC TCG AC-3' \\
gyrBR & 5'-ACC GGA ACA ACA ACG TCA AC-3' \\
katGF & 5'-GAT CAC ACC CGT GAT CAC AGC CC-3' \\
katGR & 5'-AAC GCC CAG GCC GGC TGT GA-3' \\
rpoBF & 5'-GAA TCG CGA CAG AGA TCC GGC G-3' \\
rpoBR & 5'-CCG TTC TGG GTG CAG GGG CCG T-3' \\
\hline
\end{tabular}




\section{Effect of MB on M. smegmatis}

$1 \mathrm{mg}$ of methylene blue (MB; Seoul Hwasung chemical Co Ltd) was suspended in $1 \mathrm{ml}$ of PBS (pH 6.8) and stored at $4^{\circ} \mathrm{C}$ in the dark for less than $24 \mathrm{~h}$. The effect of $\mathrm{MB}$ as a photosensitizer on the inactivation of $M$. smegmatis was examined at various concentrations $(0,1,5,10,30,50,80,150 \mu \mathrm{g} / \mathrm{ml})$. MB was suspended in $1 \mathrm{ml}$ of bacterial solutions $\left(10^{6} \mathrm{CFU} / \mathrm{ml}\right)$ and incubated in a dark room with shaking at $37^{\circ} \mathrm{C}$ for $2 \mathrm{~h}$. The solutions were serially diluted to $10^{5} \mathrm{CFU} / \mathrm{ml}, 10^{4} \mathrm{CFU} / \mathrm{ml}$, and $10^{3} \mathrm{CFU} / \mathrm{ml}$; then, $100 \mu \mathrm{l}$ of each diluted solution was spread on $7 \mathrm{H} 10$ agar plates in triplicate and incubated at $37^{\circ} \mathrm{C}$ for 2 days. The CFUs were counted on the agar plates. Each experiment was performed at least three times.

\section{Intermittent PDT (I-PDT)}

The bacterium was incubated with MB $(5 \mu \mathrm{g} / \mathrm{ml})$ for $2 \mathrm{~h}$, and then irradiated with a laser $(660 \mathrm{~nm})$ at a dose of $18 \mathrm{~J} / \mathrm{cm}^{2}$. Then the solution was incubated without additional photosensitizer for $2 \mathrm{~h}$ and irradiated with a laser at the same dose. The total irradiation dose was $36 \mathrm{~J} / \mathrm{cm}^{2}$. For the control, the bacterial sample was not irradiated after the second incubation (Fig. 1a).

\section{Repeated PDT (R-PDT)}

The bacterial solution was incubated with MB $(5 \mu \mathrm{g} / \mathrm{ml})$ for $2 \mathrm{~h}$ and irradiated with a laser $(660 \mathrm{~nm})$ at a dose of $18 \mathrm{~J} / \mathrm{cm}^{2}$. Then it was incubated with MB $(5 \mu \mathrm{g} / \mathrm{ml})$ again for $2 \mathrm{~h}$ and irradiated with a laser at a dose of $18 \mathrm{~J} / \mathrm{cm}^{2}$. As with l-PDT, the total irradiated dose was $36 \mathrm{~J} / \mathrm{cm}^{2}$. For control, the bacterial sample was not irradiated after the second MB incubation (Fig. 1b).

\section{Statistical analysis}

All statistical analysis has been carried out with Student's t-test by using GraphPad Prism version 7. Data were presented as Mean \pm SD of three independent experiments.

a

$5 \mu \mathrm{g} / \mathrm{ml}$

\section{2 hours incubation}

\begin{tabular}{|l|l} 
irradiation $18 \mathrm{~J} / \mathrm{cm}^{2}$ & $\begin{array}{l}\text { irradiation } \\
18 \mathrm{~J} / \mathrm{cm}^{2}\end{array}$ \\
2 hours incubation &
\end{tabular}

b

\begin{tabular}{|c|c|}
\hline $\begin{array}{l}\text { methylene blue } \\
5 \mu \mathrm{g} / \mathrm{ml}\end{array}$ & $\begin{array}{l}\text { irradiation } 18 \mathrm{~J} / \mathrm{cm}^{2} \\
\text { methylene blue } \\
5 \mu \mathrm{g} / \mathrm{ml}\end{array}$ \\
\hline 2 hours incubation & 2 hours incubation \\
\hline
\end{tabular}

Fig. 1. Method of intermittent PDT and repeated PDT. (a) represents intermittent PDT. M. smegmatis strains were irradiated with $18 \mathrm{~J} / \mathrm{cm}^{2}$ light dose after incubation with $5 \mu \mathrm{g} / \mathrm{ml}$ of methylene blue (MB), incubated again for 2 hours without MB exposure, and then irradiated at the same light dose $\left(18 \mathrm{~J} / \mathrm{cm}^{2}\right)$. (b) represents repeated PDT. M. smegmatis strains were irradiated with $18 \mathrm{~J} / \mathrm{cm}^{2}$ light dose after incubation with $5 \mathrm{\mu g} / \mathrm{ml}$ of MB and re-incubated with MB for $2 \mathrm{~h}$ and re-irradiated at $18 \mathrm{~J} / \mathrm{cm}^{2}$ dose of laser light. 


\section{RESULTS}

\section{Generation of multi-drug resistant mutants of $M$. smegmatis}

Multiple spontaneous drug-resistant mutants were generated by the stepwise-selection method. MIC of ciprofloxacin for the isolated ciprofloxacin-resistant $M$. smegmatis (CFXR-M. smegmatis) was $128 \mu \mathrm{g} / \mathrm{ml}$. MIC of moxifloxacin for the moxifloxacin-resistant M. smegmatis (MFXR-M. smegmatis) was $128 \mu \mathrm{g} / \mathrm{ml}$. Both CFXR and, MFXF-M. smegmatis strains were resistant to levofloxacin (Table 2). The final isolate of MDR-M. smegmatis had resistance for isoniazid (MIC $256 \mu \mathrm{g} / \mathrm{ml}$ ) and rifampicin $(1,024 \mu \mathrm{g} / \mathrm{ml})$. The fluoroquinolone-resistant MDR-M. smegmatis (FQR-MDR-M. smegmatis) had MIC of $256 \mathrm{\mu g} / \mathrm{ml}$ to the three of fluoroquinolone drugs (i.e., ciprofloxacin, moxifloxacin, and levofloxacin). Finally, FQR-MDR-M. smegmatis had the isoniazid MIC of $256 \mu \mathrm{g} / \mathrm{ml}$ and rifampicin MIC of $1,024 \mu \mathrm{g} / \mathrm{ml}$.

\section{Analysis of the genes associated with antibiotic resistance}

In three FQ resistant mutants, mutations were found in quinolone resistance-determining regions (QRDR) (25): Ala-90 Val substitution in CFXR-M. smegmatis, Asp 94 Asn substitution in MFXR-M. smegmatis and FQR-MDR-M. smegmatis (Table 2). Mutations in $r p O B$ are associated with resistance to rifampicin, the primary drug for TB (26-28). In MDR-M. smegmatis, His526 of RpoB was replaced by Asp, whereas, in FQR-MDR-M. smegmatis, Ser531 was replaced by Leu. On the other hand, no mutation was found in gyrB or katG.

\section{Inactivation of $M$. smegmatis by methylene blue (MB)}

In our previous study, MB showed a weak antimicrobial activity to $M$. smegmatis (MIC $<150 \mu \mathrm{g} / \mathrm{mL}$ ) when incubated with bacteria for $40 \mathrm{~min}$ (21). To examine whether longer incubation can increase the bactericidal activity of $\mathrm{MB}$, we incubated M. smegmatis with various concentrations of MB for $2 \mathrm{~h}$; then, bacterial CFU was counted. As with 40 min incubation, 2

Table 2. Sequencing analysis of drug-resistant Mycobacterium smegmatis and minimal inhibitory concentration of multi-drugs

\begin{tabular}{|c|c|c|c|c|c|}
\hline \multirow{2}{*}{$\begin{array}{l}\text { Sequencing analysis: } \\
\text { M. smegmatis } \\
\text { strains }\end{array}$} & \multirow[b]{2}{*}{ wild type } & \multirow[b]{2}{*}{ CFXR } & \multirow[b]{2}{*}{ MFXR } & \multirow[b]{2}{*}{ MDR } & \multirow[b]{2}{*}{ FQR-MDR } \\
\hline & & & & & \\
\hline gyrA & WT & 90Ala>Val & 94Asp>Asn & WT & 94Asp >Asn \\
\hline$g y r B$ & WT & WT & WT & WT & WT \\
\hline katG & WT & WT & WT & WT & WT \\
\hline$r p o B$ & WT & WT & WT & 526 His $>$ Asp & 531 Ser $>$ Leu \\
\hline \multicolumn{6}{|c|}{ Minimal inhibitory concentration of: } \\
\hline Ciprofloxacin & 0.125 & 128 & 256 & 0.5 & 256 \\
\hline Moxifloxacin & 0.125 & 8 & 256 & 0.5 & 256 \\
\hline Levofloxacin & 0.125 & 64 & 256 & 0.25 & 256 \\
\hline Isoniazid & 2 & 2 & 2 & 256 & 256 \\
\hline Ethambutol & 1 & 1 & 1 & 1 & 1 \\
\hline Rifampicin & 2 & 2 & 2 & 1024 & 1024 \\
\hline Streptomycin & 0.25 & 0.25 & 0.25 & 0.5 & 0.5 \\
\hline Kanamycin & 4 & 4 & 4 & 4 & 4 \\
\hline
\end{tabular}

*CFXR; ciprofloxacin resistant, MFXR; moxifloxacin resistant, MDR; multi-drug resistant, FQR-MDR; fluoroquinolone resistant multi-drug resistant 
h-incubation with MB killed M. smegmatis in a concentration-dependent manner (Fig. 2). Although it killed only $2.1 \%$ of bacteria at $5 \mu \mathrm{g} / \mathrm{ml}$, it killed $12.4 \%$ at $10 \mu \mathrm{g} / \mathrm{ml}, 24.8 \%$ at $30 \mu \mathrm{g} / \mathrm{ml}, 34.6 \%$ at $50 \mu \mathrm{g} / \mathrm{ml}$, and over $80 \%$ at $80 \mu \mathrm{g} / \mathrm{ml}$. However, even at the highest concentration (i.e., $150 \mu \mathrm{g} / \mathrm{ml}$ ), MB failed to kill all $M$. smegmatis cells. These results suggest that MB has a weak antimicrobial activity toward $M$. smegmatis, and increase of incubation time to $2 \mathrm{~h}$ does not significantly increase the antimicrobial activity of MB.

\section{Inactivation of $M$. smegmatis by PDT}

To assess the efficacy of PDT in killing $M$. smegmatis, first, we incubated the bacterium with $\mathrm{MB}(0,5$, and $30 \mathrm{mg} / \mathrm{ml})$; then, the bacterium was irradiated by a laser at $18 \mathrm{~J} / \mathrm{cm}^{2}$. We used the low concentrations of $M B$ to minimize the cytotoxicity of PDT (21). As shown, the irradiation alone did not significantly kill $M$. smegmatis (MB $0 \mathrm{mg} / \mathrm{ml}$ in Fig. 3). In the presence of $\mathrm{MB}$ (either 5 or $30 \mathrm{mg} / \mathrm{ml}$ ), however, more M. smegmatis were killed by a higher dose of irradiation (Fig. 3). In the presence of $30 \mathrm{mg} / \mathrm{ml} \mathrm{MB}$, irradiation at $54 \mathrm{~J} / \mathrm{cm}^{2}$ killed $98.2 \%$ of bacteria. These results demonstrate that PDT kills M. smegmatis in the MB and irradiation-dependent manner.

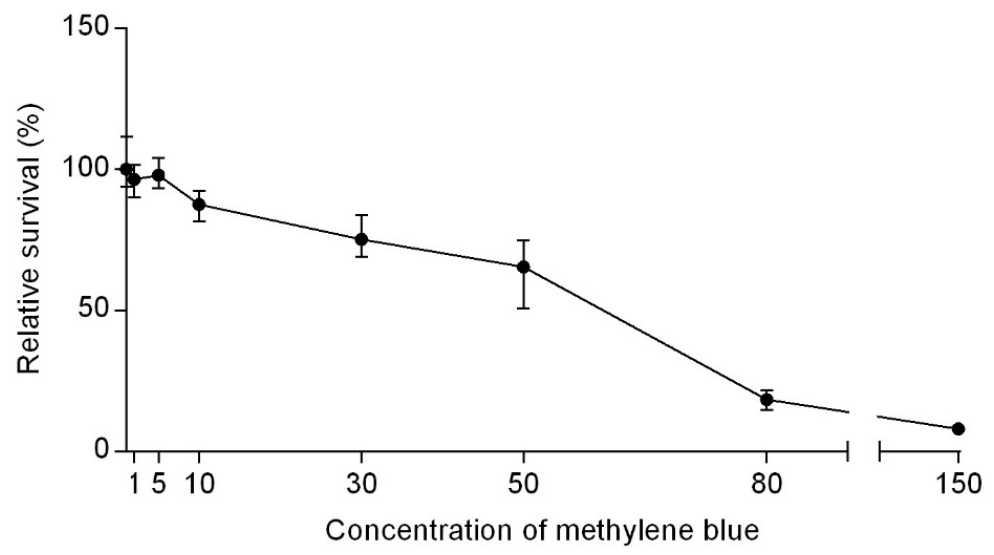

Fig. 2. The antimicrobial activity of methylene blue (MB) on Mycobacterium smegmatis. The results are mean \pm SD from three independent experiments.

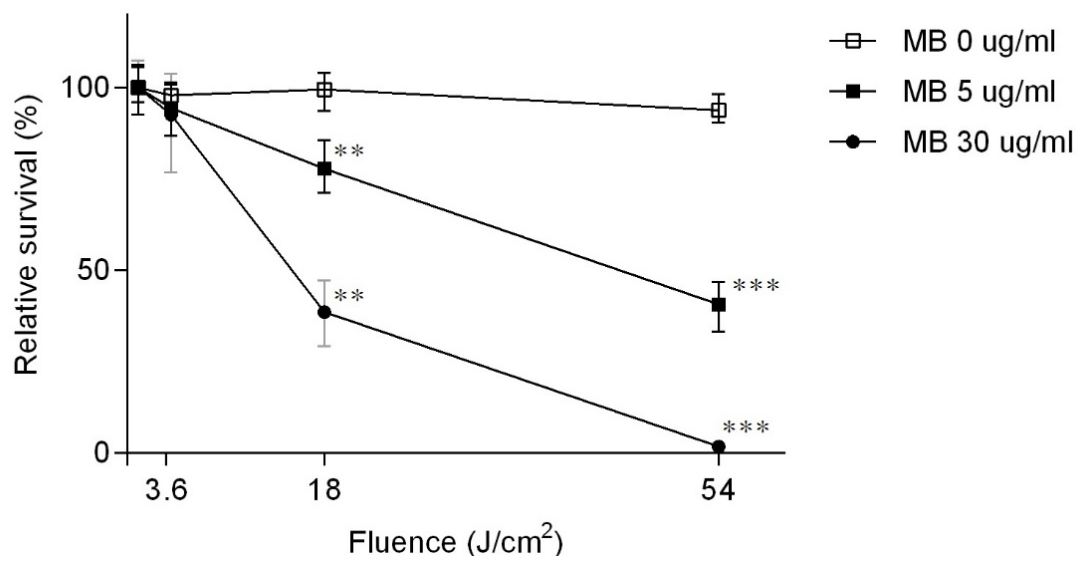

Fig. 3. The bactericidal effect of photodynamic therapy with methylene blue on Mycobacterium smegmatis. M. smegmatis was incubated in various concentrations of methylene blue $(0,5,30 \mu \mathrm{g} / \mathrm{ml})$ and irradiated with different light doses $(0,3.6$, $\left.18,54 \mathrm{~J} / \mathrm{cm}^{2}\right)$. Data were presented as mean \pm SD of three independent experiments. Asterisks indicate statistically significant differences with respect to the corresponding controls (student's t-test: $*, p<0.05 ; * *, p<0.01 ; * * *, p<0.001$ ). 


\section{The effect of drug-resistance mutations on the sensitivity to PDT}

Next, we examined the effect of drug-resistance of $M$. smegmatis on the sensitivity to PDT (see Material and Methods). The isolated spontaneous drug-resistant mutants were first incubated in various concentrations of $\mathrm{MB}(0,5, \mathrm{and} 30 \mu \mathrm{g} / \mathrm{ml})$, and then irradiated with 3.6, 18, $54 \mathrm{~J} / \mathrm{cm}^{2}$ doses of the laser. Interestingly, the drug-resistant $M$. smegmatis strains appeared more sensitive to PDT than the WT strain. Unlike the WT strain, regardless of the type of resistance, a significant number of drug-resistant strains were killed even by the low irradiation at $3.6 \mathrm{~J} / \mathrm{cm}^{2}$ and almost eradicated at $54 \mathrm{~J} / \mathrm{cm}^{2}$ (Fig. 4). These results indicate that the mycobacterial mutations commonly found in MDR and XDR-M. tuberculosis render the bacterium more susceptible to PDT.

\section{Effect of intermittent PDT (I-PDT) and Repeated PDT (R-PDT)}

Next, compared the bactericidal effect of additional radiation (i.e., I-PDT) or additional photosensitizer and radiation (i.e., R-PDT) (see Materials and Methods). PDT was carried out at $5 \mathrm{mg} / \mathrm{ml}$ of MB and either 18 or $36 \mathrm{~J} / \mathrm{cm}^{2}$ of irradiation (Fig. 5 ). In I-PDT, $2 \mathrm{~h}$ after the completion of PDT at $18 \mathrm{~J} / \mathrm{cm}^{2}$, the bacteria were subjected to additional irradiation at $18 \mathrm{~J} / \mathrm{cm}^{2}$, resulting in $36 \mathrm{~J} / \mathrm{cm}^{2}$ total irradiation. On the other hand, in R-PDT, the entire PDT procedure at $18 \mathrm{~J} / \mathrm{cm}^{2}$ was repeated. As can be seen, both I-PDT and R-PDT showed much higher bactericidal activity to $M$. smegmatis than PDT did (Fig. 5). Although PDT at $36 \mathrm{~J} / \mathrm{cm}^{2}$ killed only $56.7 \%$ of WT bacteria, both I-PDT and R-PDT killed more than 93\% (Fig. 5a). The
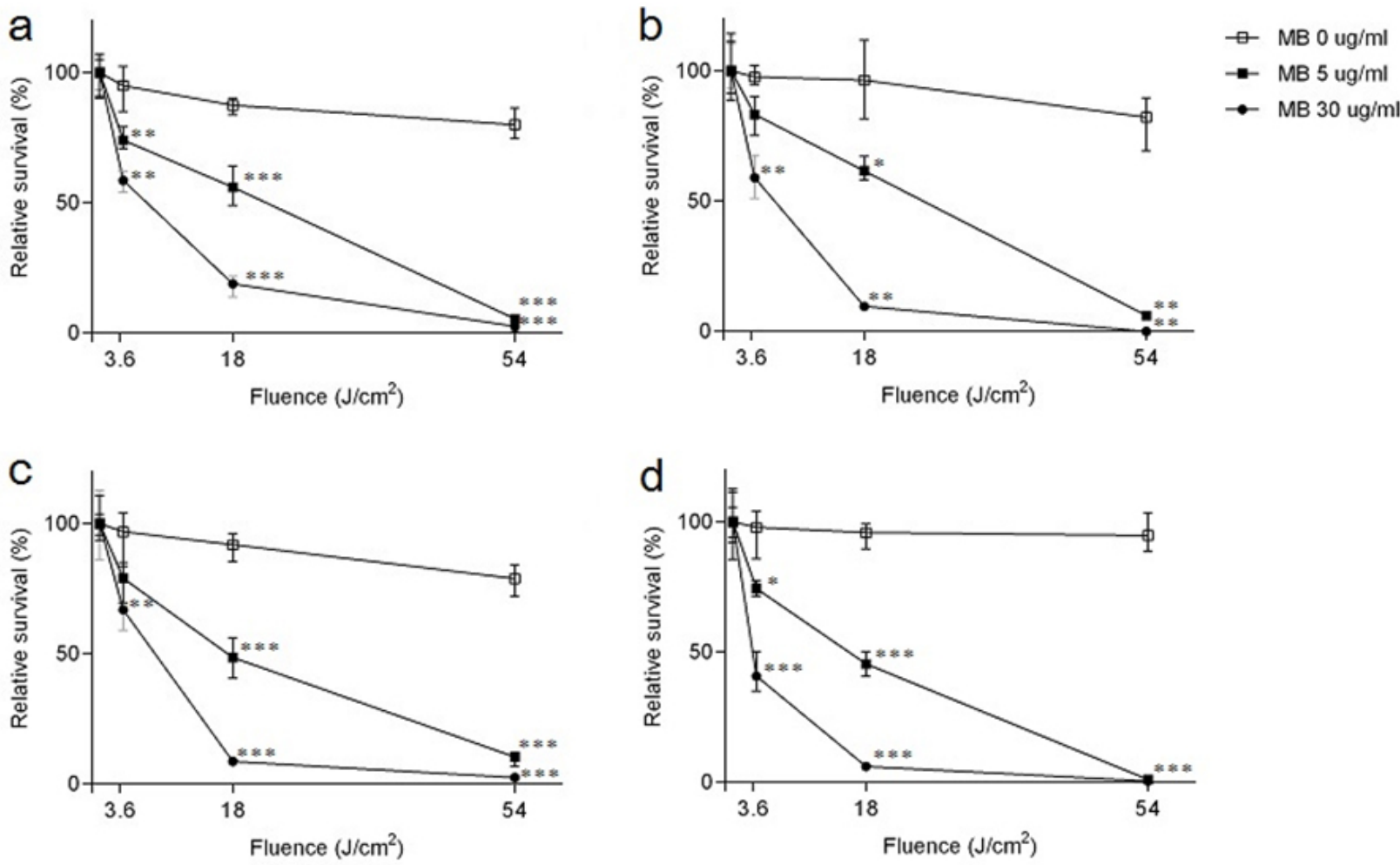

Fig. 4. Effects of photodynamic therapy with methylene blue on drug-resistant Mycobacterium smegmatis. Drug-resistant $M$. smegmatis strains were incubated in various concentrations of methylene blue $(0,5,30 \mu \mathrm{g} / \mathrm{ml})$ and irradiated at different light doses $\left(0,3.6,18,54 \mathrm{~J} / \mathrm{cm}^{2}\right)$. (a-d) represents ciprofloxacin resistant-, moxifloxacin resistant-, multi drug-resistant (MDR)-, fluoroquinolone-resistant MDR-M. smegmatis strain, respectively. Data were presented as Mean \pm SD of three independent experiments. Asterisks indicate statistically significant differences with respect to the corresponding controls (student's t-test: $*, p<0.05 ; * *, p<0.01 ; * * *, p<0.001)$. 
higher bactericidal activity of I-PDT and R-PDT was also evident for drug-resistant bacteria (Fig. 5b-e). As expected, control groups for I-PDT and R-PDT did not show significant inactivation of $M$. smegmatis. These results demonstrate that I-PDT and R-PDT with a low concentration of methylene blue as a photosensitizer can be an effective treatment option for mycobacterial infections, regardless of the drug-resistance of the bacterium.
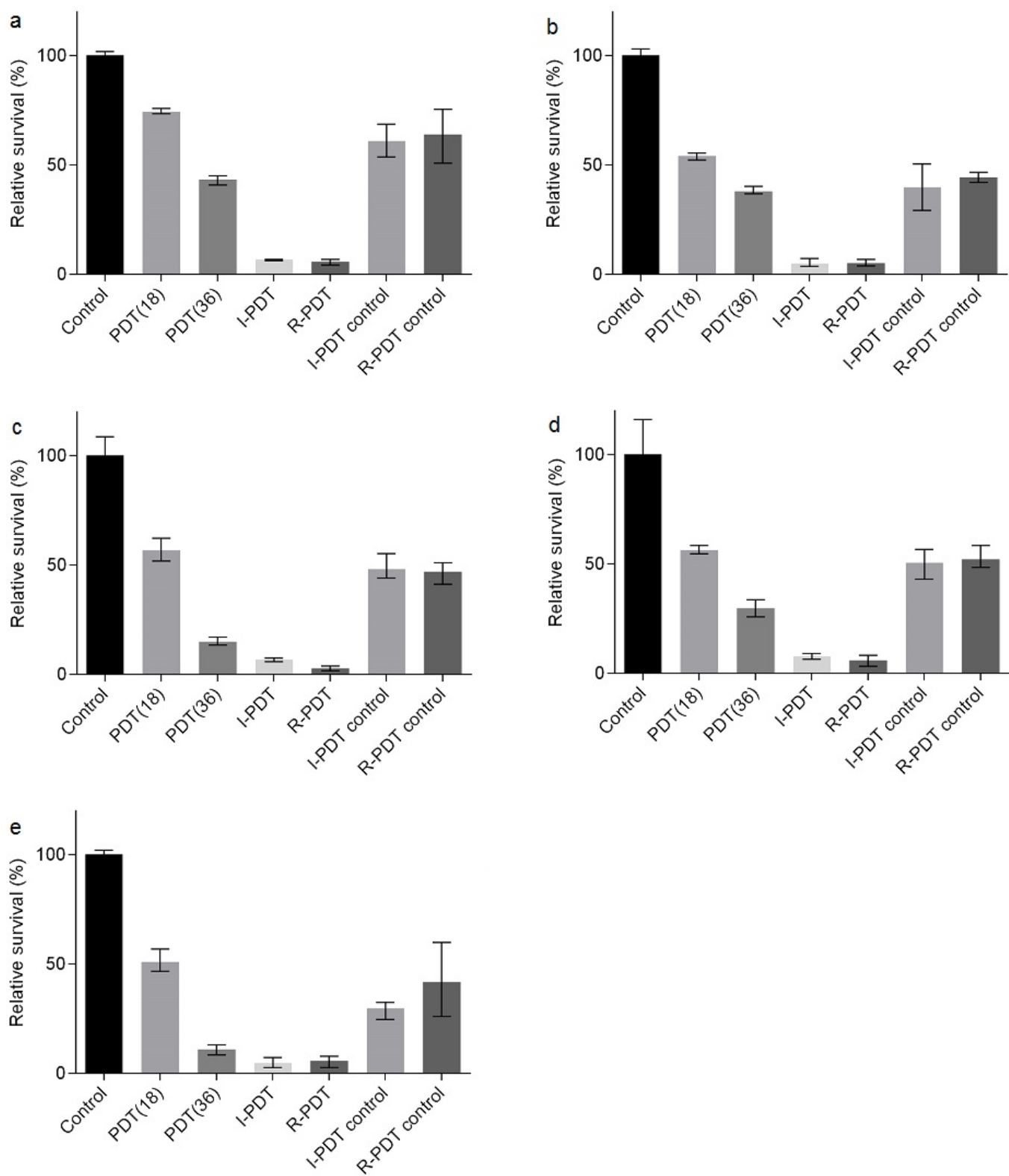

Fig. 5. The survival rate of Mycobacterium smegmatis by intermittent PDT and repeated PDT. (a-e) represents a wild type-, ciprofloxacin resistant-, moxifloxacin resistant, multi drug-resistant (MDR)-, fluoroquinolone-resistant MDR-M. smegmatis strain, respectively. For comparison of intermittent PDT and repeated PDT, $M$. smegmatis strains were irradiated for a continuous double time period of those PDT, resulting in $36 \mathrm{~J} / \mathrm{cm}^{2}$ of irradiation dose. Control: no photosensitizer and laser light, PDT $18 \mathrm{~J} / \mathrm{cm}^{2}$ : continuous PDT at the dose of $18 \mathrm{~J} / \mathrm{cm}^{2}$, PDT $36 \mathrm{~J} / \mathrm{cm}^{2}$ : continuous PDT at the dose of $36 \mathrm{~J} / \mathrm{cm}^{2}$, I-PDT: intermittent PDT, R-PDT: repeated PDT, I-PDT control: $M$. smegmatis strains were treated by PDT at the dose of $18 \mathrm{~J} / \mathrm{cm}^{2}$ and incubated for 2 hours without methylene blue $(\mathrm{MB})$ exposure and irradiation. R-PDT control: $M$. smegmatis strains were treated by PDT at the dose of $18 \mathrm{~J} / \mathrm{cm}^{2}$ and incubated with $\mathrm{MB}$ for 2 hours, but not irradiation. Data were presented as mean \pm SD of three independent experiments. 


\section{DISCUSSION}

TB is an old disease that has affected humans for thousands of years. The WHO estimates that approximately 2 billion peoples are currently living with the causative agent $M$. tuberculosis (1). Although antibiotic therapy has been effective in TB treatment, its lengthy treatment time, multiple antibiotics requirements, and the drug side-effects hampered the effectiveness of the therapy. Also, the emergence of multidrug-resistant strains made TB treatment more difficult and calls for new therapeutics. Here, we showed that PDT with MB as a photosensitizer could efficiently kill the model organism $M$. smegmatis. More importantly, PDT killed drug-resistant strains more efficiently, making PDT with MB an attractive treatment method for TB caused by multi-drug resistant mycobacteria, notably, in the resource-scarce setting.

Along with rifampicin, isoniazid is a primary TB drug. As a pro-drug, isoniazid is activated by KatG (catalase peroxidase) of mycobacterium. Once activated, isoniazid forms a covalent complex with InhA (enoyl-ACP reductase) and blocks the synthesis of mycolic acid $(28,29)$. Mutations in KatG can confer the bacterium resistance to isoniazid, and the replacement at 275 threonine or 300 tryptophan is most frequent $(30,31)$. In this study, however, we did not find any mutation in the katG gene of MDR-M. smegmatis strain (Table 2), indicating that the isoniazid resistance of the strain is probably due to mutations in other genes known to be involved in isoniazid resistance (e.g., inhA, acp $M$, and kasA).

To M. smegmatis, the photosensitizer MB showed weak antimicrobial activity (MIC > $150 \mathrm{mg} / \mathrm{ml}$, Fig. 2), whereas the laser irradiation itself has almost no antimicrobial activity (Fig. 3). However, when both were combined, they showed dramatic synergy and efficiently killed M. smegmatis (Fig. 3), implying that the major mode of bactericidal activity of PDT is through the production of reactive oxygen species $(11,12)$. It is known that DNA is sensitive to reactive oxygen species (32). Interestingly, the drug-resistant strains contain mutations in proteins that bind to DNA for their functions (i.e., GyrA and/or RpoB). The increased sensitivity of drug-resistant strains to PDT (Fig. 4) might indicate that those mutated proteins might function less efficiently with the damaged DNA. However, further research is needed to delineate the relationship between the sensitivity to PDT and the type of antibiotic resistance.

In PDT, the repetition of the irradiation step alone (i.e., I-PDT) significantly increased the bactericidal activity. For example, when PDT was carried out at $36 \mathrm{~J} / \mathrm{cm}^{2}$, it only killed $57 \%$ of WT M. smegmatis (Fig. 5a). However, with I-PDT, where irradiation of $18 \mathrm{~J} / \mathrm{cm}^{2}$ was repeated, and the total irradiation was $36 \mathrm{~J} / \mathrm{cm}^{2}, 93 \%$ were killed. Since there was no significant difference between I-PDT and R-PDT, the extra addition of MB is not necessary for the enhanced bactericidal activity in this in vitro setting, where the $M B$ concentration remains constant. However, in the in vivo treatment setting, where the MB concentration will become lower by diffusion, R-PDT is expected to be more efficient in killing bacteria.

The bactericidal activity of PDT could be further improved. Daniela et al. reported the combination of photosensitizer MB with potassium iodide enhanced the killing of $S$. aureus and $E$. coli with PDT (33). Shih et al. also reported that the mix of CFX, MFX, or amikacin to MB enhanced the bactericidal activity of PDT (34). Therefore, the efficient mycobacterial killing of I-PDT/R-PDT used in this study might be further enhanced by such additions. If this is the case, it will further improve the potential of PDT as an alternative therapeutic method for TB treatment and contribute to lessening the burden of antimicrobial resistance of mycobacterium.

\section{REFERENCES}

1) World Health Organization. Global tuberculosis report 2020. Licence: CC BY-NC-SA 3.0 IGO.

2) LoBue P, Sizemore C, Castro K. Plan to combat extensively drug-resistant tuberculosis recommendations of the federal tuberculosis task force. MMWR Recomm Rep 2009:58:1-43. 
3) Korea centers for Disease Control and Prevention. Annual report on the notified tuberculosis in Korea. 2020.

4) Bliss JM, Bigelow CE, Foster TH, Haidaris CG. Susceptibility of Candida species to photodynamic effects of photofrin. Antimicrob Agents Chemother 2004;48:2000-6.

5) Dougherty TJ. Photodynamic therapy. Photochem Photobio/ 1993;58:895-900.

6) Weishaupt KR, Gomer CJ, Dougherty TJ. Identification of singlet oxygen as the cytotoxic agent in photoinactivation of a murine tumor. Cancer Res 1976:36:2326-9.

7) Dougherty TJ, Gomer CJ, Henderson BW, Jori G, Kessel D, Korbelik M, et al. Photodynamic Therapy. J Nat/ Cancer Inst 1998;90:889-905

8) Maunoury V, Mordon S, Bulois P, Mirabel X, Hecquet B, Mariette C. Photodynamic therapy for early oesophageal cancer. Dig Liver Dis 2005;37:491-5.

9) Cuenca RE, Allison RR, Sibata C, Downie GH. Breast cancer with chest wall progression: treatment with photodynamic therapy. Ann Surg Oncol2004;11:322-7.

10) Jones BU, Helmy M, Brenner M, Serna DL, Williams J, Chen JC, et al. Photodynamic therapy for patients with advanced non-small-cell carcinoma of the lung. Clin Lung Cancer 2001;3:37-41.

11) Wilson M, Mia N. Sensitization of Candida albicans to Killing by low power laser light. J Oral Patho/ Med 1993:22:354-7.

12) Fontana CR, Abernethy AD, Som S, Ruggiero K, Doucette S, Marcantonio RC, et al. The antibacterial effect of photodynamic therapy in dental plaque-derived biofilms. J Periodontal Res 2009;44:751- 9.

13) Garland MJ, Cassidy CM, Woolfson D, Donnelly RF. Designing photosensitizers for photodynamic therapy: strategies, challenges and promising developments. Future Med Chem 2009;1:667-91.

14) Huang L, Xuan $Y$, Koide $Y$, Zhiyentayev T, Tanaka M, Hamblin MR. Type I and Type II mechanisms of antimicrobial photodynamic therapy: An in vitro study on gram-negative and gram-positive bacteria. Lasers Surg Med 2012:44:490-9.

15) Wiegell SR, Kongshoj B, Wulf HC. Mycobacterium marinum Infection Cured by Photodynamic Therapy. Arch Dermatol 2006;142:1241-2.

16) O’Riordan K, Sharlin DS, Gross J, Chang S, Errabelli D, Akilov OE, et al. Photoinactivation of Mycobacteria in vitro and in a new murine model of localized Mycobacterium bovis BCG-induced granulomatous infection. Antimicrob Agents Chemother 2006:50:1828-34.

17) Sung N, Back S, Jung J, Kim KH, Kim JK, Lee JH, et al. Inactivation of multidrug resistant (MDR)- and extensively drug resistant (XDR)-Mycobacterium tuberculosis by photodynamic therapy. Photodiagnosis Photodyn Ther 2013;10:694-702.

18) de Oliveira BP, Aguiar CM, Câmara AC. Photodynamic therapy in combating the causative microoraganisms from endodentic infections. Eur J Dent 2014;8:424-30.

19) Klepac-Ceraj V, Patel N, Song X, Holewa C, Patel C, Kent R, et al. Photodynamic effects of methylene blue-loaded polymeric nanoparticles on dental plaque bacteria. Lasers surg Med 2011:43:600-6.

20) Siddiqui SH, Awan KH, Javed F. Bacterial efficacy of photodynamic therapy against Enterococcus faecalis in infected root canals: a systematic literature review. Photodiagnosis Photodyn Ther 2013;10:632-43.

21) Shim I, Choi M, Min Y, Seok KH, Kim JK, Jeong JY, et al. Effect of methylene blue-mediated photodynamic therapy on wild-type and ciprofloxacin-resistant Mycobacterium smegmatis. J Bacterio/ Viro/2016:46:27-35. 
22) Titgemeyer F, Amon J, Parche S, Mahfoud M, Bail J, Schlicht M, et al. A genomic view of sugar transport in Mycobacterium smegmatis and Mycobacterium tuberculosis. J Bacterio/2007;189:5903-15.

23) Liu H, Yang M, He ZG. Novel TetR family transcriptional factor regulates expression of multiple transport-related genes and affects rifampicin resistance in Mycobacterium smegmatis. Sci Rep 2016:6:27489.

24) Ferrero L, Cameron B, Crouzet J. Analysis of gyrA and grlA mutations in stepwise-selected ciprofloxacin-resistant mutants of Staphylococcus aureus. Antimicrob Agents Chemother 1995:39:1554-8.

25) Takiff HE, Salazar L, Guerrero C, Philipp W, Huang WM, Kreiswirth B, et al. Cloning and nucleotide sequence of Mycobacterium tuberculosis gyrA and gyrB genes and detection of quinolone resistance mutations. Antimicrob Agents Chemother 1994;38:773-80.

26) Anek-Vorapong R, Sinthuwattanawibool C, Podewils LJ, McCarthy K, Ngamlert K, Promsarin B, et al. Validation of the Geno Type MTBDR plus assay for detection of MDR-TB in a public health laboratory in Thailand. BMC Infect Dis 2010;10:123.

27) Hillemann D, Rüsch-Gerdes S, Richter E. Evaluation of the Geno Type MTBDR plus assay for rifampin and isoniazid susceptibility testing of Mycobacterium tuberculosis strains and clinical specimens. J Clin Microbio/2007;45:2635-40.

28) Ramaswamy S, Musser JM. Molecular genetic basis of antimicrobial agent resistance in Mycobacterium tuberculosis: 1998 update. Tuber Lung Dis 1998;79:3-29.

29) Musser JM. Antimicrobial agent resistance in mycobacteria: molecular genetic insights. Clin Microbio/ Rev 1995:8:496-514.

30) Wei CJ, Lei B, Musser JM, Tu SC. Isoniazid activation defects in recombinant Mycobacterium tuberculosis catalaseperoxidase (KatG) mutants evident in InhA inhibitor production. Antimicrob Agents Chemother 2003;47:670-5.

31) Rouse DA, DeVito JA, Li Z, Byer H, Morris SL. Site-directed mutagenesis of the katG gene of Mycobacterium tuberculosis: effects on catalase-peroxidase activities and isoniazid resistance. Mol Microbio/ 1996:22:583-92.

32) Cadet J, Wagner JR. DNA base damage by reactive oxygen species, oxidizing agents, and UV radiation. Cold Spring Harb Perspect Bio/2013:5:a012559.

33) Vecchio D, Gupta A, Huang L, Landi G, Avci P, Rodas A, et al. Bacterial photodynamic inactivation mediated by methylene blue and red light is enhanced by synergistic effect of potassium iodide. Antimicrob Agents Chemother 2015;59:5203-12.

34) Shih $\mathrm{MH}$, Huang FC. Effects of photodynamic therapy on rapidly growing nontuberculous mycobacteria keratitis. Invest Ophthalmol Vis Sci2011;52:223-9. 